Current Research Journal of Biological Sciences 10(1): 1-6, 2018

DOI:10.19026/crjbs. 10.5920

ISSN: 2041-076X, e-ISSN: 2041-0778

(C) 2018 Maxwell Scientific Publication Corp.

\begin{tabular}{lll}
\hline Submitted: June 27, 2018 & Accepted: July 24, 2018 & Published: November 20, 2018
\end{tabular}

\title{
Research Article \\ Effect of Intramuscular Administration of Trypadim, Trypamidium and Novidium on Body Temperature, Body Weight and Hematological Parameters of Wistar Rats Infected with Trypanosoma brucei brucei (Federe Strain)
}

\author{
${ }^{1}$ J.J. Ajakaiye, ${ }^{2}$ M.S. Benjamin, ${ }^{3}$ A.A. Muhammad, ${ }^{3}$ R.L. Bizi, ${ }^{4}$ B. Mohammed, \\ ${ }^{4}$ M.R. Mazadu and ${ }^{5}$ K.E. Okoh \\ ${ }^{1}$ Pan African Tsetse and Trypanosomiasis Eradication Campaign Department, \\ ${ }^{2}$ Onchocerciasis Research Department, \\ ${ }^{3}$ Animal African Trypanosomiasis Research Department, \\ ${ }^{4}$ Extension Services Unit, Consultancy and Extension Services Division, \\ ${ }^{5}$ Vector and Parasitological Studies Research Department, Nigerian Institute for Trypanosomiasis (and \\ Onchocerciasis) Research, No. 1 Surame Road, P. M. B 2077, U/Rimi, Kaduna, Nigeria
}

\begin{abstract}
Effect of intramuscular administration of Trypanocides on body temperature, body weight and hematological parameters of Wistar rats infected with Trypanosoma brucei brucei was investigated. Twenty-five adult Wistar rats were randomly divided into 5 groups. Group A uninfected untreated, group B were infected with $1 \times 10^{6}$ of the parasites. Groups C, D and E were administered the same dose as in group B and were treated with 3.5 $\mathrm{mg} / \mathrm{kg}$ b.w. of Trypadim ${ }^{\circledR}$ (Diminazene di-aceturate); $1 \mathrm{mg} / \mathrm{kg} \mathrm{b.w.} \mathrm{of} \mathrm{Trypamidium}{ }^{\circledR}$ (Isometamidium chloride) and $1 \mathrm{mg} / \mathrm{kg}$ b.w. of Novidium ${ }^{\circledR}$ (Homidium chloride), respectively. PCV, WBC, Neutrophil were significantly $(\mathrm{p}<0.05)$ higher in groups C, D and E compared to group B. However, the same level of significance $(p<0.05)$ was observed for eosinophil but in a decreasing pattern. Body temperature increased consistently in all groups except group A. There was a significant $(\mathrm{p}<0.05)$ difference in all treated groups compared to group $\mathrm{B}$ on day 7 and 28 postinfection. Body weight decreased significantly $(\mathrm{p} \leq 0.01)$ in group B compared to the initial and final values. Both vitamins in their separate administration demonstrated trypanocidal and anti-pyrexia activities and therefore we recommend further studies of their combined usage in order to evaluate its synergistic effect in combating or ameliorating the problem of drug resistance in trypanosomiasis.
\end{abstract}

Keywords: Body temperature, hematological parameters, novidium ${ }^{\circledR}$, trypadim ${ }^{\circledR}$, trypamidium ${ }^{\circledR}$, Trypanosoma brucei brucei (Federe strain), wistar rats

\section{INTRODUCTION}

Trypanosomiasis is considered as one of the most neglected tropical diseases (Truc, 2003). For several decades, the disease has continued to contribute adversely to the economic and social well being of subSaharan Africans (WHO, 2006; Adeyemi et al., 2009). This great suffering remains a pressing challenge especially to African medical scientists for a possible action plan that would include both preventive measures and treatment modalities (Okochi et al., 2003). Animal trypanosomiasis (Nagana or Sammoré) is caused by Trypanosoma brucei brucei, T. congolense and T. vivax; because of their presence in the blood, these invading parasites produce numerous changes in the cellular and biochemical constituents of blood (Igbokwe and Mohammed, 1992; Taiwo et al., 2003). Among the different species of Trypanosome, the subspecies Trypasonoma brucei brucei (Federe strain) has been known to be the most virulent with gradual developing wavy anemia as a common pathogenic characteristic infection in mammals (Anosa, 1988). The disease is characterized by various non-specific clinical signs such as fever, lacrimation, anemia, jaundice, wasting of muscles, infertility, weight loss and low milk production (Radostitis et al., 2003; Kennedy, 2004;

\footnotetext{
Corresponding Author: J.J. Ajakaiye, Pan African Tsetse and Trypanosomiasis Eradication Campaign Department, Nigerian Institute for Trypanosomiasis (and Onchocerciasis) Research, No. 1 Surame Road, P. M. B 2077, U/Rimi, Kaduna, Nigeria, Tel.: +234 8082935228

This work is licensed under a Creative Commons Attribution 4.0 International License (URL: http://creativecommons.org/licenses/by/4.0/).
} 
Ekanem and Yusuf, 2008; Akanji et al., 2009). Despite many decades of research and actions at vector and chemoprophylactic/chemotherapeutic control of trypanosomiasis, effective control strategies are yet to materialize. The methods of using chemotherapeutic drugs for treatment and prophylaxis as well as insecticides for vector control have met with unsatisfactory outcomes (Eghianruwa and Anika, 2012). However, chemotherapy and chemoprophylaxis still remain the main methods of control of the disease as there is yet no breakthrough in the production of a vaccine against this menace (Olurode et al., 2009). It has been documented that most drugs in use were produced half a century ago and resistance and toxicity are associated with most of them (Ajagbonna and Onyeyili, 2003; Ezeokonkwo et al., 2007). New drug development for the control of trypanosomiasis is unappealing for commercial reasons (Trouiller and Olliaro, 1999; Murray et al., 2000). The challenge, thus, remains to make optimal use of the 3 relatively old compounds until new methods of treatment emerge through research activities (Adamu et al., 2009) and no report on research carried out using these drugs in its combined form in a single experiment has been previously documented. In conclusion, therefore, we have investigated the effect of 3 trypanocidal drugs; TRYPADIM $^{\circledR} \quad$ (Diminazene di-aceturate),

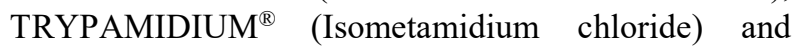
NOVIDIUM $^{\circledR}$ (Homidium chloride) on hematological parameters, body temperature and live body weight in Wistar rats infected with $T$. brucei brucei. (Federe strain).

\section{MATERIALS AND METHODS}

Experimental site: The study was conducted at the Nigerian Institute for Trypanosomiasis and (Onchocerciasis) Research (NITR) and located in Kaduna North Local Government Area of Kaduna State. Kaduna State is located at latitude $10^{\circ} 30^{\prime} 00^{\prime \prime} \mathrm{N}$ and longitude $7^{\circ} 25^{\prime} 50^{\prime \prime}$ E of Nigeria, Africa.

Experimental animals: The study was conducted under protocols in the guidelines established by the "Guide for the Care and use of Laboratory Animals" (Institute of Laboratory Animal Resources, National Academy of Science, Washington D.C., 1996). Twentyfive adult Wistar rats weighing between 200 and $240 \mathrm{~g}$ were obtained from the rat colony of NITR. The animals were randomly divided into 5 groups, of five rats each and kept in well ventilated, standard plastic cages $15 \times 22 \times 10 \mathrm{~m}^{3}$ dimension as follows:

Group A: Uninfected, untreated

Group B: Infected but not treated

Group C: Infected and treated with TRYPADIM
Group D: Infected and treated with TRYPAMIDIUM

Group E: Infected and treated with NOVIDIUM

The animals were fed with a pelleted basal diet obtained from a commercial feed outlet (Vital Feeds Plc., Kaduna, Nigeria) and water was given ad-libitum.

Measurement of body temperature and bodyweight: The body temperature in all animals from all groups were measured once daily between the $\mathrm{h}$ of 1200 and $1500 \mathrm{pm}$. Briefly each animal was gently caught and a digital thermometer with a maximum gauge of $42^{\circ} \mathrm{C}$ (accuracy $\pm 0.1^{\circ} \mathrm{C}$ MODE: ECT-1, MAXICOM), was inserted $3 \mathrm{~cm}$ into and by the wall of the colorectum of each rat and at the sound of a beep, the thermometer was immediately withdrawn and values obtained recorded accordingly. However, life body weight of all animals in all the groups was taken twice/week and throughout the experimental period with the aid of a standard electronic weighing balance (Salter, Pocket Balance, England) with a maximum calibration of $5 \mathrm{~kg}$ and a precision of $0.1 \mathrm{~g}$.

Trypanosome infection: Trypanosoma brucei brucei (Federe strain) was obtained from the cryogen kept in the Department of Vector and Parasitology Research, NITR, Kaduna, Nigeria. The infected blood from donor rat at peak parasitemia (4 DPI) was collected by means of tail picking and diluted with cold physiological saline. The numbers of parasites in the diluted blood were determined through the method described by Herbert and Lumsden (1976). A volume containing approximately $1 \times 10^{6}$ was injected intraperitoneally into each rat in the infected groups, respectively.

Drugs administered: All drugs used were obtained from a commercial outfit in Kaduna, Nigeria. The drugs were products of the same Company (Merial, 29, Avenue Tony Garnier, 69007 Lyon, France) which were all administered as a single dose from the onset of parasitemia. Briefly, the drugs were dissolved and reconstituted in distilled water according to manufacturer's instruction and given intramuscularly in the following concentrations: TRYPADIM at 3.5 $\mathrm{mg} / \mathrm{kg} /$ bodyweight; TRYPAMIDIUM at 1.0 $\mathrm{mg} / \mathrm{kg} /$ bodyweight and NOVIDIUM at $1.0 \mathrm{mg} / \mathrm{kg} /$ body weight, respectively.

Blood sample collection and measurement of hematological profiles: Tail blood was collected daily for monitoring parasitemia as described by Herbert and Lumsden (1976) and blood samples were taken using heparinized tubes to determine the PCV using the micro-hematocrit method. At 28 DPI, the rats were sacrificed by humane decapitation and blood samples were collected for hematological studies. White Blood 
Table 1: Summary of total number of dead animals and animals cleared of parasites during the experimental period

\begin{tabular}{llllll}
\hline Group & A & B & C & D & E \\
\hline Total number of deaths & 0 & 5 & 0 & 0 & 1 \\
No. of animals cleared of parasitaemia & 0 & 0 & 5 & 5 & 4 \\
\hline
\end{tabular}

Cell (WBC), neutrophils, lymphocytes and eosinophils counts were determined using the Automated Hematology Analyzer, (SYSMEX, KX-21, Japan) as described by Dacie and Lewis (1991).

Statistical analyses: All data were presented as means \pm SEM and analyzed by one way ANOVA. The data of live body weight were analyzed using student paired t-test and expressed as means \pm SEM. In addition, differences between means were compared through the post-hoc test method described by Duncan (1955) with aid of the SPSS version 19 statistical package and values of $(p<0.05)$ were considered significant.

\section{RESULTS}

The treated groups in Table 1 were cleared of parasites and survived for the period of 28 days of the experiment. Group B died prior to day- 28 with one dead in group $\mathrm{E}$ towards the tail end of the experiment.

Hematological parameters observed in Table 2 of animals in group B revealed low count in PCV, WBC, neutrophil, eosinophil and lymphocyte that were significantly $(\mathrm{p}<0.05)$ different compared to groups $\mathrm{C}$, $\mathrm{D}$ and E. Eosinophil was observed to decrease significantly $(p<0.05)$ in group B than the rest of the groups.

Table 3 shows the results of body temperature observed in all the groups infected. There was a consistent increase in the values of body temperature recorded in the infected groups when compared to negative control. This increase as it was observed in group B is highly significant $(\mathrm{p}<0.05)$ than the rest of the groups at 7DPI and 28DPI, followed by 14DPI and 21DPI in all the groups.

Table 4 presents results of initial and final live body weight recorded in all the groups. Decrease in live body weight was observed in groups $\mathrm{B}, \mathrm{C}$ and $\mathrm{E}$ when compared to group A and is highly significant $(p \leq 0.01)$ in group B. However, in the case of groups A and D, there was no significant $(p>0.05)$ difference observed in the final values compared to the initial values.

\section{DISCUSSION}

The result of hematological parameters obtained from this study such as PCV, WBC, neutrophil, eosinophil and lymphocyte has been documented to be of great importance to livestock health and production status (Oyewale and Fajimi, 1988), this statement is further supported by the studies of Ekanem et al. (2005, 2006) who established and documented that, the measurement of anemia gives a reliable indication of the disease status and productive performance of trypanosome-infected animals. Anemia is recognized as the most important clinical manifestation of animal trypanosomiasis while PCV is used as an indicator in evaluating the level of anemia. In this experiment, the packed cell volume observed decreased significantly $(p<0.05)$ in group B when compared to the values of group A and the treated groups. The low PCV observed in the infected groups especially group B could be as a result of acute hemolysis due to growing infection. This agrees with several studies reported by Ogunsanmi and Taiwo (2001), Umar et al. (2007), Ekanem et al. (2008), Saleh et al. (2009) and Sulaiman and Adeyemi (2010) which stated that acute anemia in trypanosomiasis reflects the intensity and duration of parasitemia. Our findings in this study is in agreement with the reports of Richardson and Kendall (1963), which in their studies observed anemia with reduction

Table 2: Effect of intramuscular administration of trypadim, trypamidium and novidium on some haematological parameters of wistar rat infected with Trypanosoma brucei brucei

\begin{tabular}{lllll}
\hline Groups & Uninfected untreated & Infected not treated & $\begin{array}{l}\text { Infected and treated } \\
\text { with trypadim }\end{array}$ & $\begin{array}{l}\text { Infected and treated with } \\
\text { trypamidium }\end{array}$ \\
\hline PCV & $49.10 \pm 0.53^{\mathrm{a}}$ & $28.80 \pm 0.34^{\mathrm{e}}$ & $45.70 \pm 0.27^{\mathrm{c}}$ & $47.50 \pm 0.32^{\mathrm{b}}$ \\
WBC & $14.18 \pm 0.14^{\mathrm{a}}$ & $6.86 \pm 0.11^{\mathrm{e}}$ & $10.62 \pm 0.15^{\mathrm{c}}$ & $12.85 \pm 0.14^{\mathrm{b}}$ \\
wected and treated & $41.90 \pm 0.38^{\mathrm{d}}$ & $09.32 \pm 0.09^{\mathrm{d}}$ \\
Eosinophil & $31.11 \pm 0.33^{\mathrm{a}}$ & $9.97 \pm 0.14^{\mathrm{e}}$ & $14.18 \pm 0.12^{\mathrm{d}}$ & $23.43 \pm 0.30^{\mathrm{b}}$ \\
Lymphocyte & $17.54 \pm 0.15^{\mathrm{a}}$ & $2.84 \pm 0.14^{\mathrm{d}}$ & $06.64 \pm 0.13^{\mathrm{c}}$ & $17.80 \pm 0.13^{\mathrm{c}}$ \\
\hline Eatrophil & $91.74 \pm 0.28^{\mathrm{a}}$ & $53.89 \pm 4.36^{\mathrm{c}}$ & $74.24 \pm 4.33^{\mathrm{b}}$ & $6.57 \pm 0.13^{\mathrm{c}}$ \\
\hline
\end{tabular}

Each mean values of 5 determinations \pm Standard Error of Mean (S.E.M.) with different superscripts in the same column are significantly (p $<0.05$ ) different

Table 3: Effect of intramuscular administration of trypadim, trypamidium and novidium on body temperature in wistar rats infected with

\begin{tabular}{llllll}
\multicolumn{2}{c}{ Trypanosoma brucei brucei } & & \\
\hline Groups & Uninfected untreated & Infected not treated & $\begin{array}{l}\text { Infected and treated } \\
\text { with trypadim }\end{array}$ & $\begin{array}{l}\text { Infected and treated with } \\
\text { trypamidium }\end{array}$ & $\begin{array}{l}\text { Infected and treated } \\
\text { with novidium }\end{array}$ \\
\hline Initial & $37.52 \pm 0.16^{\mathrm{c}}$ & $37.42 \pm 0.24^{\mathrm{c}}$ & $37.49 \pm 0.15^{\mathrm{c}}$ & $37.50 \pm 0.19^{\mathrm{c}}$ & $37.51 \pm 0.14^{\mathrm{c}}$ \\
7DPI & $37.56 \pm 0.20^{\mathrm{c}}$ & $39.86 \pm 0.18^{\mathrm{a}}$ & $38.37 \pm 0.14^{\mathrm{b}}$ & $38.05 \pm 0.19^{\mathrm{ab}}$ & $38.45 \pm 0.16^{\mathrm{b}}$ \\
14DPI & $37.55 \pm 0.16^{\mathrm{c}}$ & $38.45 \pm 0.12^{\mathrm{b}}$ & $37.95 \pm 0.13^{\mathrm{b}}$ & $37.80 \pm 0.15^{\mathrm{bc}}$ & $37.96 \pm 0.15^{\mathrm{b}}$ \\
21DPI & $37.41 \pm 0.19^{\mathrm{c}}$ & $38.81 \pm 0.14^{\mathrm{b}}$ & $38.13 \pm 0.12^{\mathrm{ab}}$ & $38.05 \pm 0.16^{\mathrm{ab}}$ & $38.24 \pm 0.19^{\mathrm{ab}}$ \\
28DPI & $37.53 \pm 0.14^{\mathrm{c}}$ & $39.94 \pm 0.22^{\mathrm{ab}}$ & $37.74 \pm 0.13^{\mathrm{bc}}$ & $37.56 \pm 0.15^{\mathrm{bc}}$ & $38.05 \pm 0.13^{\mathrm{ab}}$ \\
\hline Each mean values of 5 determinations \pm Standard Error of Mean (S.E.M.) with different superscripts in the same column are significantly (p<0.05)
\end{tabular}

Each mean values of 5 determinations \pm Standard Error of Mean (S.E.M.) with different superscripts in the same column are significantly (p $<0.05$ ) difference 
Table 4: Trypanocide comparison of mean body weight (initial and final) of wistar rats infected with Trypanosoma brucei brucei $(\mathrm{n}=5)$

\begin{tabular}{lllrl}
\hline Groups & Initial & Final & $\mathrm{t}$ & $\mathrm{p}$-value \\
\hline $\mathrm{A}$ & $222.30 \pm 3.72$ & $223.30 \pm 3.91$ & -1.369 & 0.204 \\
$\mathrm{~B}$ & $222.10 \pm 5.97$ & $193.00 \pm 2.07$ & 4.005 & $0.003^{* *}$ \\
$\mathrm{C}$ & $222.00 \pm 4.67$ & $218.30 \pm 4.03$ & 2.185 & 0.057 \\
$\mathrm{D}$ & $221.10 \pm 5.30$ & $221.60 \pm 4.12$ & -0.117 & 0.910 \\
$\mathrm{E}$ & $222.40 \pm 5.47$ & $216.60 \pm 4.26$ & 1.771 & 0.110 \\
\hline \multicolumn{4}{l}{ Level of significant difference along rows exists at $* *: \mathrm{p} \leq 0.01$}
\end{tabular}

in the number of Red Blood Cells (RBC) to the level of $25 \%$ of the normal value and also that of Igbokwe and Nwosu (1997) which eventually in their reports concluded that, trypanosome infection may cause anemia as a result of massive erythro-phagocytosis by an expanded and active Mononuclear Phagocytic System (MPS) of the host. However, the increase observed in PCV of the treated groups could be as a result of the trypanocidal activity of the drugs. Leucopenia, neutropenia and lymphopenia observed in the infected not treated group (i.e., group B) when compared to groups $\mathrm{C}, \mathrm{D}$ and $\mathrm{E}$, could be due to the immunosuppressive activities of trypanosome infection (Abubakar et al., 2005; Ekanem and Yusuf, 2008). Although there were significant $(p<0.05)$ difference in the neutrophil and lymphocyte values observed in the treated groups. On the other hand significant $(\mathrm{p}<0.05)$ decrease was observed in the values of eosinophil in group B when compared to the treated groups, this is because eosinophil is important in body defense against tissue parasites. Leucocytosis and lymphocytosis have been implicated in trypanosomiasis and these conditions are usually as a result of wax and wear syndrome on the animal immune system caused by the ever-changing variable surface glycoprotein of the infecting trypanosomes (Abubakar et al., 2005). However these lesions were reduced significantly $(p<0.05)$ in the infected animals treated with Trypadim, Trypamidium and Novidium, with the Trypamidium group significantly $(\mathrm{p}<0.05)$ higher than the rest, respectively. Result suggests that administered drugs had improved blood parameters in the treated groups, possibly by depletion of rapidly growing parasites, thereby prolonging the life of the rats.

The increase in body temperature (fever) is a typical symptom of trypanosomiasis, which reflects the response to successive waves of parasitemia as documented in the report of Stephen (1986). Our finding is in agreement with that of Baracos et al. (1987) when they reported that the body temperature set point in the hypothalamus was then changed under the influence of pyrogenic stimuli released during infection. The consistent increase in body temperature (Table 3) as it was observed at 7DPI and 21DPI in all the infected groups, with group $\mathrm{B}$ higher than the rest at 7DPI and 28DPI when compared to group A, may be as a result of the infection due to proliferating trypanosomes that leads to pyrexia. This statement is supported by Masimba et al. (2012) who reported that infection with $T$. brucei brucei caused hyperthermia $\left(39.1^{\circ} \mathrm{C}\right)$ and disrupted cyclicity in the experimental rats. These changes, however, were reduced significantly $(\mathrm{p}<0.05)$ in the groups treated with drugs at 14DPI and 28DPI as shown in this study, suggesting attempts by the administered drugs to display antipyrexia activities and return cellular activities toward normal when compared to the pre-infection state. These probably enhanced the development of phagocytic cells and antibodies against the recognizable antigens of parasite origin.

The live body weight was highly significantly $(p \leq 0.01)$ reduced in group B when compared to groups treated with the drugs. This weight loss could be as a result of trypanosome infection. Moreover, there was no significant $(p>0.01)$ difference observed in values recorded for groups $\mathrm{A}$ and $\mathrm{E}$. This finding agrees with the report of Itard (1989) which stated that the clearly seen weight loss was due to increase in parasitemia.

\section{CONCLUSION}

Based on the result obtained in this study, we confirm the efficacy of TRYPADIM ${ }^{\circledR}$, TRYPAMIDIUM $^{\circledR}$ and NOVIDIUM ${ }^{\circledR}$ in the control and treatment of African trypanosomiasis. This is against the backdrop that the use of these trypanocides have long been in existence and therefore the parasite has been able to develop resistance against its efficacy. Resistance may be due to associated iatrogenic factors such as the use of substandard/fake drugs, application of under/overdosage, to outright ignorance in the application of the drugs. We, therefore, recommend further studies into their possible combined usage or alternate usage in order to evaluate their synergistic effect in combating the menace of this disease in subSaharan Africa.

\section{CONFLICT OF INTEREST}

The authors hereby wish to state categorically that there was no financial/or other relevant interest that has influenced the development of this manuscript.

\section{REFERENCES}

Abubakar, A., B. Iliyasu, A.B. Yusuf, A.C. Igweh, N.A. Onyekwelu, B.U. Shamaki, D.O. Afolayan et al., 2005. Antitrypanosomal and haematological effects of selected Nigerian medicinal plants in Wistar rats. Biokemistri, 17(2): 95-99.

Adamu, S., N. Barde, J.N. Abenga, N.M. Useh, N.D.G. Ibrahim and K.A.N. Esievo, 2009. Experimental Trypanosoma brucei infectioninduced changes in the serum profiles of lipids and cholesterol and the clinical implications in pigs. J. Cell Anim. Biol., 3(2): 015-020. 
Adeyemi, O.S., M.A. Akanji and S.A. Oguntoye, 2009. Ethanolic leaf extract of Psidium guajava: Phytochemical and trypanocidal activity in rats infected with Trypanosoma brucei brucei. J. Med. Plants Res., 3(5): 420-423.

Ajagbonna, O.P. and P.A. Onyeyili, 2003. Effects of aqueous extract of Allium sativum (Garlic) on haematological and biochemical parameters in rabbits infected with Trypanosoma brucei. Proceeding of 8th Annual Conference of Animal Science Association of Nigeria, (ASAN) Federal University of Technology and Animal Science, Minna, pp: 95-97.

Akanji, M.A., O.S. Adeyemi, S.O. Oguntoye and F. Sulyman, 2009. Psidium guajava extract reduces trypanosomosis associated lipid peroxidation and raises glutathione concentrations in infected animals. EXCLI J., 8: 148-154.

Anosa, V.O. 1988. Haematological and biochemical changes in human and animal trypanosomiasis. Part I. Rev. Elev. Med. Vet. Pays Trop., 41(1): 65-78.

Baracos, V.E., W.T. Whitmore and R. Gale, 1987. The metabolic cost of fever. Can. J. Physiol. Pharmacol., 65(6): 1248-1254.

Dacie, J.V. and S.M. Lewis, 1991. Practical Hematology. 7th Edn., Churchill Livingston, Edinburg.

Duncan, D.B., 1955. Multiple range and multiple F tests. Biometrics, 11(1): 1-42.

Eghianruwa, K.I. and S.M. Anika, 2012. Effects of DMSO on diminazene efficacy in experimental murine T. brucei infection. Int. J. Anim. Vet. Adv., 4(2): 93-98.

Ekanem, J.T. and O.K. Yusuf, 2008. Some biochemical and haematological effects of black seed (Nigella sativa) oil on T. brucei-infected rats. Afr. J. Biomed. Res., 11: 79-85.

Ekanem, J.T., F.A. Sulaiman and O. Adeyemi, 2005. Therapeutic properties and serum iron in $T$. brucei infected rats treated with amodiaquine and mefloquine. Biokemistri, 17(2): 115-121.

Ekanem, J.T., O.M. Kolawole and O.C. Abbah, 2008. Trypanocidal potential of methanolic extract of Bridelia ferruginea benth bark in Rattus novergicus. Afr. J. Biochem. Res., 2(2): 045-050.

Ekanem, J.T., O.R. Majolagbe, F.A. Sulaiman and N.O. Muhammad, 2006. Effects of honeysupplemented diet on the parasitemia and some enzymes of Trypanosoma brucei-infected rats. Afr. J. Biotechnol., 5: 1557-1561.

Ezeokonkwo, R.C., F.C. Okoro and I.O. Ezeh, 2007. The efficacy of increasing doses of Samorenil ${ }^{\circledR}$ in the treatment of Trypanosoma brucei infected Albino rats. Nigerian Vet. J., 28(2): 24-32.

Herbert, W.J. and W.H.R. Lumsden, 1976. Trypanosoma brucei: A rapid "matching" method for estimating the host's parasitemia. Exp. Parasitol., 40(3): 427-431.
Igbokwe, I.O. and A. Mohammed, 1992. Some plasma biochemical changes in experimental Trypanosoma brucei infection of Sokoto red goats. Rev. Elev. Med. Pays. Trop., 45(3-4): 287-290.

Igbokwe, I.O. and C.O. Nwosu, 1997. Lack of correlation of anaemia with splenomegaly and hepatomegaly in Trypanosoma brucei and Trypanosoma congolense infections of rats. J. Comp. Pathol., 117(3): 261-265.

Itard, J., 1989. African Animal Trypanosomiasis. In: English (Ed.), Manual of Tropical Veterinary Parasitology. CAB International, Wallingford, Oxon, UK, pp: 179-290.

Kennedy, P.G.E., 2004. Human African trypanosomiasis of the CNS: Current issues and challenges. J. Clin. Invest., 113(4): 496-504.

Masimba, N.J., N.G. Magak, M. Ndiema, R. Odera, L. Chemwolon, M.D. Minjire and D.K. Ndungu, 2012. Disruption of reproductive cycles in rats (Rattus norvegicus) acutely infected with Trypanosoma brucei brucei is associated with Hyperthermia and, ovarian and pituitary gland tissue degenerations. Afr. J. Health Sci., 22: 233-237.

Murray, H.W., J. Pépin, T.B. Nutman, S.L. Hoffman and A.A.F. Mahmoud, 2000. Tropical medicine. BMJ, 320(7233): 490-494.

Ogunsanmi, A.O. and V.O. Taiwo, 2001. Pathobiochemical mechanisms involved in the control of the disease caused by Trypanosoma congolense in African grey duiker (Sylvicapra grimmia). Vet. Parasitol., 96(1): 51-63.

Okochi, V.I., J. Okpuzor, M.O. Okubena and A.K. Awoyemi, 2003. The influence of African herbal formula on the haematological parameters of trypanosome infected rats. Afr. J. Biotech., 2(9): 312-316.

Olurode, S.A., O.P. Ajagbonna, K.T. Biobaku, H. Ibrahim and M.I. Takeet, 2009. Efficacy study of zinc chloride and diminazene aceturate on trypanosoma brucei inoculated rats. J. Nat. Sci. Eng. Technol., 8(2): 38-43.

Oyewale, J.O. and J.L. Fajimi, 1988. The effects of egg-laying on haematological and plasma biochemistry of guinea hen. Bull. Anim. Health Prod. Afr., 36: 229-232.

Radostitis, O.M., C.C. Gay, D.C. Blood and K.W. Hinchclift, 2003. Diseases of Domestic Animals. 9th Edn., Britain, UK, pp: 1330-1334.

Richardson, U.F. and S.B. Kendall, 1963. Veterinary Protozoology. Oliver and Boyd Publishers Ltd., pp: 55.

Saleh, M.A., M.B. Al Salahy and S.A. Sanousi, 2009. Oxidative stress in blood of camels (Camelus dromedaries) naturally infected with Trypanosoma evansi. Vet. Parasitol., 162(3-4): 192-199.

Stephen, L.E., 1986. Trypanosomiasis: A Veterinary Perspective. 1st Edn., Pergamon Press, New York. 
Sulaiman, F.A. and O.S. Adeyemi, 2010. Changes in haematological indices and protein concentrations in Trypanosoma brucei infected rats treated with homidium chloride and diminazene aceturate. EXCLI J., 9: 39-45.

Taiwo, V.O., M.O. Olaniyi and A.O. Ogunsanmi, 2003. Comparative plasma biochemical changes and susceptibility of erythrocytes to in vitro peroxidation during experimental Trypanosoma congolense and Trypanosoma brucei infections in sheep. Israel J. Vet. Med. Assoc., 58: 1-10.

Trouiller, P. and P.L. Olliaro, 1999. Drug development output from 1975 to 1996: What proportion for tropical diseases? Int. J. Infect. Dis., 3: 61-63.
Truc, P., 2003. About Trypanosoma brucei gambiense, the causative agent of the chronic form of Human African Trypanosomiasis: Some findings and proposals. Afr. J. Biotechnol., 2(12): 657-661.

Umar, I.A., E. Ogenyi, D. Okodaso, E. Kimeng, G.I. Stancheva et al., 2007. Amelioration of anaemia and organ damage by combined intraperitoneal administration of vitamins $\mathrm{A}$ and $\mathrm{C}$ to Trypanosoma brucei brucei-infected rats. Afr. J. Biotechnol., 6(18): 2083-2086.

WHO, 2006. African Trypanosomosis (sleeping sickness). Fact Sheet 259. World Health Organization, Geneva, Switzerland. 